\title{
Oxide-assisted crack growth in hold-time low-cycle-fatigue of single-crystal superalloys
}

\author{
Akane Suzuki ${ }^{1, a}$, Yan Gao ${ }^{1}$, Don Lipkin ${ }^{1}$, Anjali Singhal ${ }^{1}$, Matthew Krug${ }^{2}$, Douglas Konitzer ${ }^{2}$, Jonathan Almer ${ }^{3}$, \\ Tresa Pollock ${ }^{4}$, and Bernard Bewlay ${ }^{1}$ \\ ${ }^{1}$ GE Global Research, Niskayuna, NY, USA \\ ${ }^{2} \mathrm{GE}$ Aviation, Cincinnati, OH, USA \\ ${ }^{3}$ Argonne National Laboratory, Advanced Photon Source, Lemont, IL, USA \\ ${ }^{4}$ University of California, Santa Barbara, Santa Barbara, CA, USA
}

\begin{abstract}
Compressive hold-time low-cycle fatigue is one of the important damage modes in Ni-based superalloy hot-gas path components. In strain controlled LCF, the compressive hold typically degrades fatigue life significantly due to creep relaxation and the resultant generation of tensile stress upon returning to zero strain. Crack initiation typically occurs on the surface, and therefore, the cracks are covered with layers of oxides. Recent finite element modeling based on experimental observations has indicated that the in-plane compressive stress in the alumina layer formed on the surface of the bond coat assists rumpling and, eventually, leads to initiation of cracks. The stress in the oxide layer continues to assist crack extension by pushing the alumina layer along the crack front during the compressive hold. In-situ measurements of the growth strains of alumina were performed using high energy synchrotron X-rays at Argonne National Lab. Specimens of single-crystal superalloys with and without aluminide coatings were statically pre-oxidized to form a layer of alumina at 1093 and $982^{\circ} \mathrm{C}$. For the in-situ synchrotron measurements, the specimens were heated up to the pre-oxidation temperatures with a heater. The alumina layers on both bare and coated specimens show compressive in-plane strains at both temperatures. The oxide strains on the superalloys showed dependency on temperature; on the other hand, the oxide strains in the aluminide coatings were insensitive to temperature. The magnitude of the compressive strains was larger on the superalloys than the ones on the aluminide coatings.
\end{abstract}

\section{Crack growth in hold-time LCF of single-crystal Ni-base superalloys}

Resistance to compressive hold-time low-cycle-fatigue (LCF) deformation is one of the important properties required for Ni-base single-crystal superalloys used for internally cooled airfoil components in aircraft engines and land based gas turbines for power generation. Strain controlled compressive hold-time LCF deformation is significantly damaging to the superalloys, because creep deformation during the compressive hold causes the generation of tensile stress upon returning to zero strain. The tensile stress causes initiation and propagation of surface cracks which eventually lead to failure of the material. In a series of interrupted compressive hold-time LCF tests conducted at $1093^{\circ} \mathrm{C}$ and $0.35 \%$ total strain range using a second generation single-crystal superalloy, René N5 coated with vapor phase aluminide (VPA), it was observed that (i) the surface crack initiation occurred in the early stage $(<10 \%)$ of the fatigue life and (ii) the surface cracks were covered with an $\alpha-\mathrm{Al}_{2} \mathrm{O}_{3}$ layer due to the exposure to the air [1]. Figure 1 shows a

\footnotetext{
${ }^{a}$ Corresponding author: suzukia@ge.com
}

typical crack observed in the bond coat layer (Fig. 1a) and a crack propagated into the single-crystal superalloy substrate (Fig. 1b) beyond the bond coat layer and the interdiffusion zone.

It has been known that the $\alpha-\mathrm{Al}_{2} \mathrm{O}_{3}$ layer formed on the surfaces of the bond coats of the superalloys typically have in-plane compressive growth strains due to the volume expansion during oxidation, and that the compressive stress of the oxide layer contributes to the evolution of bond coat rumpling during cyclic oxidation environment [2]. Evans et al. [3-5] examined the role of compressive growth strains of the $\alpha-\mathrm{Al}_{2} \mathrm{O}_{3}$ layer in extension of a crack in isothermal compressive cyclic loading using a finite element model, and predicted that the compressive stress of the $\alpha-\mathrm{Al}_{2} \mathrm{O}_{3}$ layer causes crack extension by inward extrusion of the $\alpha-\mathrm{Al}_{2} \mathrm{O}_{3}$ layer along the crack front during compressive loading. The predicted crack growth rate was close to the crack growth rate observed in the interrupted specimens. The model predicted that larger compressive growth strains of the $\alpha$ $\mathrm{Al}_{2} \mathrm{O}_{3}$ cause higher crack growth rates in both the bond coat layer and the superalloy substrate.

In-situ measurements of the oxide growth strains have been conducted by Veal et al. [6-11] and Almer et al. [12] using synchrotron X-rays. The evolution of 

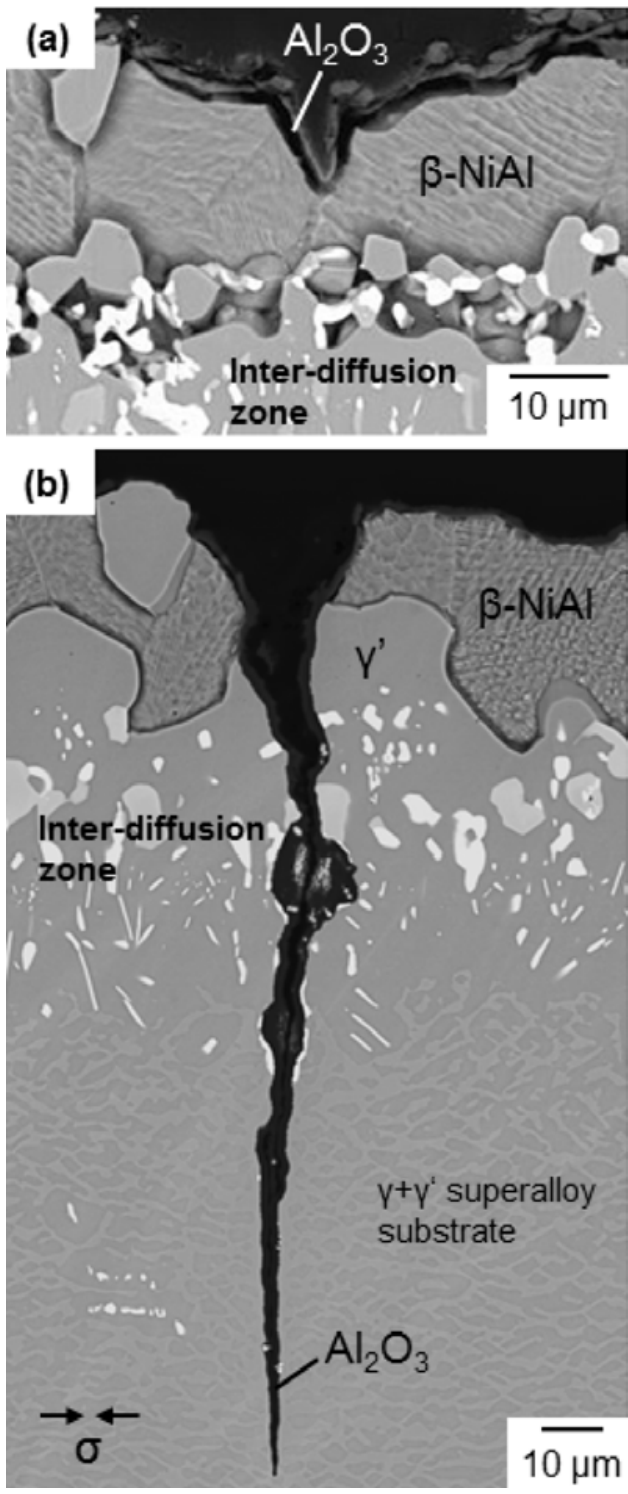

Figure 1. Surface cracks covered with the $\alpha-\mathrm{Al}_{2} \mathrm{O}_{3}$ layer in (a) the bond coat layer and (b) the superalloy substrate.

the growth strains in the early stage of the oxidation, the creep behaviour of the oxide layer and the effects of alloy chemistry on the oxide growth strains have been investigated using various $\beta$-NiAl-based and NiCrAlY alloys. However, there has been a lack of high temperature in-situ measurements of the growth strains of the oxide layers formed on single-crystal superalloys and industrial bond coats, except a limited study that used room temperature strain measurements by laser scanning confocal microscopy and thermal expansion data to calculate the oxide growth strains that were generated during prior oxidation at elevated temperatures [13,14].

In this study, in-situ measurements of the oxide growth strains were conducted using the oxide layers grown on a single-crystal Ni-base superalloy and a $\beta$-NiAl based industrial bond coat. The measurement results and effect of temperature, effect of bond coat composition will be discussed.

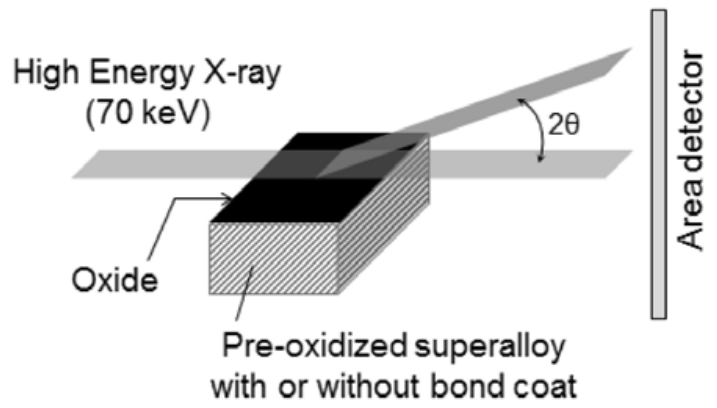

Figure 2. Schematic illustration of the experimental setup.

\section{Experimental procedures}

The experimental arrangement is illustrated in Fig. 2. In this experiment, a transmission diffraction approach was applied for the oxide growth strain measurements. Compared with the grazing incident diffraction mode used by Veal et al. [6-11], the transmission diffraction mode used by Almer et al. [12] requires high energy X-rays to penetrate through the material. As the oxide layer thickness is $\sim 1 \mu \mathrm{m}$, such high energy X-rays must be from a high brilliance source. The experimental procedure for the transmission diffraction mode is simpler than grazing incident diffraction mode, because it is easier to find the beam center and to align the specimen: both are critical for accurate strain analysis.

The high energy synchrotron X-ray diffraction experiment was performed at Beamline 1-ID-C at Advanced Photon Source, Argonne National Laboratory. A Ni-based René N5 single-crystal superalloy and a $\beta$ NiAl-based vapor phase aluminide bond coat were selected for the experiments. The bond coat was deposited on a single-crystal superalloy substrate. Both bare and coated superalloy specimens were machined to $6 \mathrm{~mm}$ wide, $10 \mathrm{~mm}$ long, $3 \mathrm{~mm}$ thick coupons. Prior to the strain measurements, the coupons were isothermally oxidized in air for 68 hours at either $1093{ }^{\circ} \mathrm{C}$ or $982^{\circ} \mathrm{C}$ to grow oxide layers in advance, to achieve stable state of the oxide growth.

The measurements were conducted at both room temperature and the same high temperatures at which the specimens were pre-oxidized. To heat the pre-oxidized coupons during the in-situ measurements, a commercial $\mathrm{SiC}$ igniter was used. The surface of the igniter was coated with a protective layer to prevent reaction with the superalloy specimens.

During the in-situ measurements, the sample surface temperatures were monitored by a pyrometer mounted above the sample, and were determined based on a lattice parameter of Pt powders placed on the surfaces of the samples. Slurry containing Pt powders and yttria-stabilized zirconia (YSZ) powders was painted to partly cover the oxidized surfaces of the coupons. The YSZ powders were used to prevent the Pt particles from coalescing during high temperature exposure. The thermal expansion of $\mathrm{Pt}$ was used for determining the temperature of the oxide layer.

The diffraction data was collected by a GE twodimensional detector, using $70 \mathrm{keV} \mathrm{X}$-rays focused to a $20 \mu \mathrm{m}$ high and $200 \mu \mathrm{m}$ wide rectangle shape. 

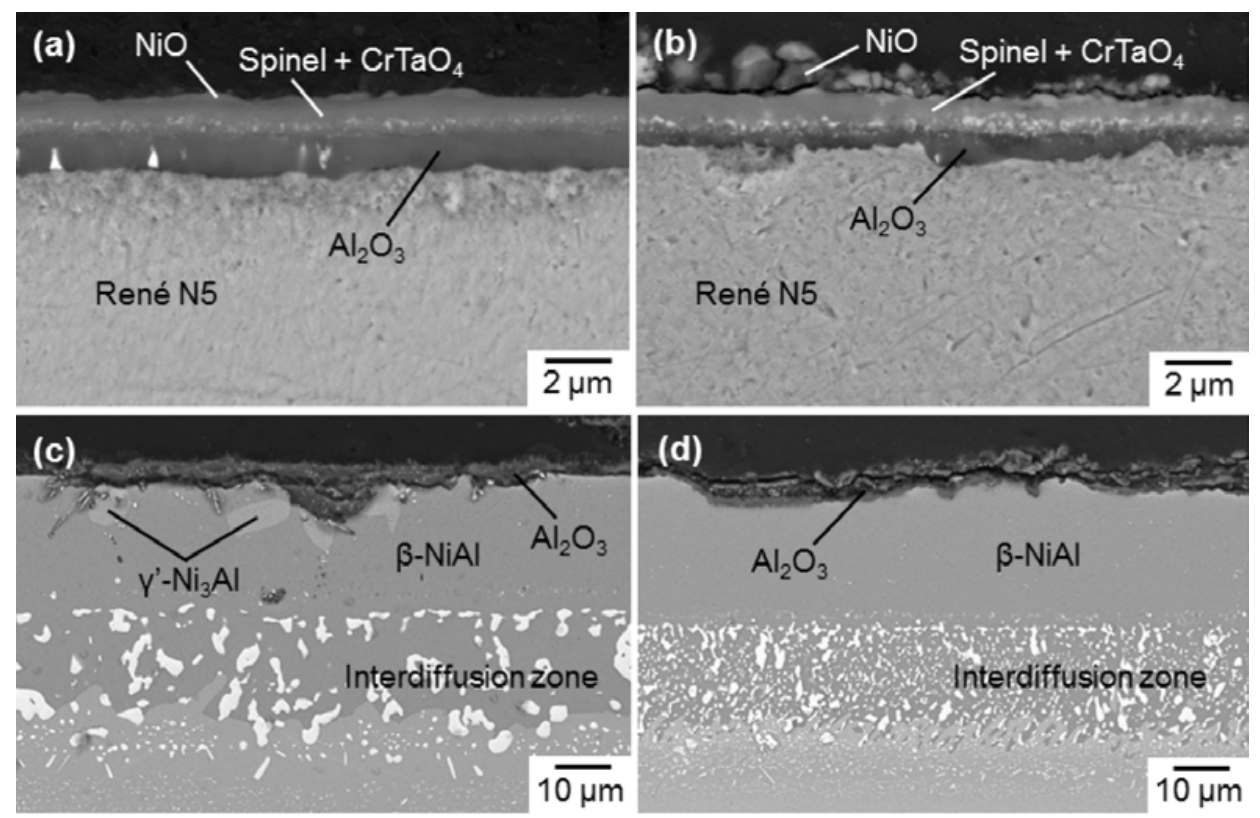

Figure 3. Backscattered electron images of the pre-oxidized specimens: (a) René N5, $1093^{\circ} \mathrm{C} / 68 \mathrm{~h}$, (b) René N5, $982^{\circ} \mathrm{C} / 68 \mathrm{~h}$, (c) vapor phase aluminide coating, $1093^{\circ} \mathrm{C} / 68 \mathrm{~h}$, (d) vapor phase aluminide coating, $982^{\circ} \mathrm{C} / 68 \mathrm{~h}$.

The beam center and detector distortion were determined using unstrained ceria powder diffraction pattern. Inplane strain was obtained from the elliptical distortion of the diffraction rings using $\sin ^{2} \psi$ method $[6,12,15]$. The elliptical distortion, $D$, is

$$
D=\left(d_{\psi=0^{\circ}}-d_{\psi=90^{\circ}}\right) / d_{\psi=0^{\circ}} .
$$

Where $d_{\psi=0^{\circ}}$ is the in-plane lattice spacing and $d_{\psi=90^{\circ} \text { is the }}$ out-of-plane lattice spacing for a given $(h k l)$. The sign of this quantity identifies a tensile $(+)$ and compressive $(-)$ condition. Quantities of $d_{\psi=0^{\circ}}$ and $d_{\psi=90^{\circ}}$ were obtained by fitting diffraction ring of $\alpha-\mathrm{Al}_{2} \mathrm{O}_{3}$ (116) based on the 2D diffraction formulas by $\mathrm{He}$ et al. [17] using the MATLAB program by Almer et al. [12]. Among the $\alpha$ $\mathrm{Al}_{2} \mathrm{O}_{3}$ reflections, the (116) reflection was chosen, because it is a high order reflection with a relatively high intensity and no overlap with reflections from other oxides. To quantify the in-plane strain state $\varepsilon_{11}$, it was assumed that the oxide is an isotropic distribution of crystallites in a biaxially stressed film with no shear based on the observation of the diffraction rings showing absence of strong texture in the $\alpha-\mathrm{Al}_{2} \mathrm{O}_{3}$ layer (Sect. 3.2.1).

For this case, it can be shown that

$$
\varepsilon_{11} \approx D(1-v) /(1+v)
$$

where $v$ is Poisson's ratio, and that the stress $\sigma_{11}$ is

$$
\sigma_{11} \approx E \varepsilon_{11} /(1-v)
$$

where $E$ is Young's modulus.

Table 1 shows Young's modulus, E, and Poisson's ratio, $v$, of $\alpha-\mathrm{Al}_{2} \mathrm{O}_{3}$ at the room temperature, $982^{\circ} \mathrm{C}$, $1093^{\circ} \mathrm{C}$ used for the strain and stress calculations. Based on our assessment of literature data, the values measured by Sakaguchi et al. [18] and Fukuhara et al. [19] using pure bulk $\alpha-\mathrm{Al}_{2} \mathrm{O}_{3}$ were selected.
Table 1. Young's modulus and Poisson's ratio of $\alpha-\mathrm{Al}_{2} \mathrm{O}_{3}$ used for the strain and stress calculations.

\begin{tabular}{|l|l|l|}
\hline Temperature & $\begin{array}{l}\text { Young's } \\
\text { modulus } \\
(\mathbf{G P a})\end{array}$ & $\begin{array}{l}\text { Poisson's } \\
\text { ratio }\end{array}$ \\
\hline Room temperature & 380 & 0.24 \\
\hline $982^{\circ} \mathrm{C}$ & 330 & 0.25 \\
\hline $1093{ }^{\circ} \mathrm{C}$ & 322 & 0.25 \\
\hline
\end{tabular}

\section{Results and discussions}

\subsection{Oxide structure}

The backscattered electron images of the oxide layers formed on the bare René N5 single-crystal superalloy and the vapor phase aluminde coating specimens after the exposure for 68 hours at $1093^{\circ} \mathrm{C}$ and $982^{\circ} \mathrm{C}$ are shown in Fig. 3.

At both temperatures, the René N5 specimen formed three layers of oxides: a $\mathrm{NiO}$ external layer, a spinel $\left(\mathrm{Ni}(\mathrm{Al}, \mathrm{Cr})_{2} \mathrm{O}_{4}\right)$ layer where fine particles of $\mathrm{CrTaO}_{4}$ were embedded, and an $\alpha-\mathrm{Al}_{2} \mathrm{O}_{3}$ layer adjacent to the superalloy substrate. The thickness of the $\alpha-\mathrm{Al}_{2} \mathrm{O}_{3}$ layer was about $1 \mu \mathrm{m}$ after the exposure at $1093^{\circ} \mathrm{C}$, and about $0.5 \mu \mathrm{m}$ after the exposure at $982{ }^{\circ} \mathrm{C}$. The thickness of the spinel layer was about $1 \mu \mathrm{m}$ at both temperatures.

The vapor phase aluminide coating specimens formed a layer of $\alpha-\mathrm{Al}_{2} \mathrm{O}_{3}$ after the exposure at $1093{ }^{\circ} \mathrm{C}$ and $982^{\circ} \mathrm{C}$. The thickness was about $3 \mu \mathrm{m}$. In the coupon oxidized at $1093{ }^{\circ} \mathrm{C}$, formation of $\gamma^{\prime}-\mathrm{Ni}_{3} \mathrm{Al}$ phase was observed beneath the $\alpha-\mathrm{Al}_{2} \mathrm{O}_{3}$ layer due to the consumption of $\mathrm{Al}$. 


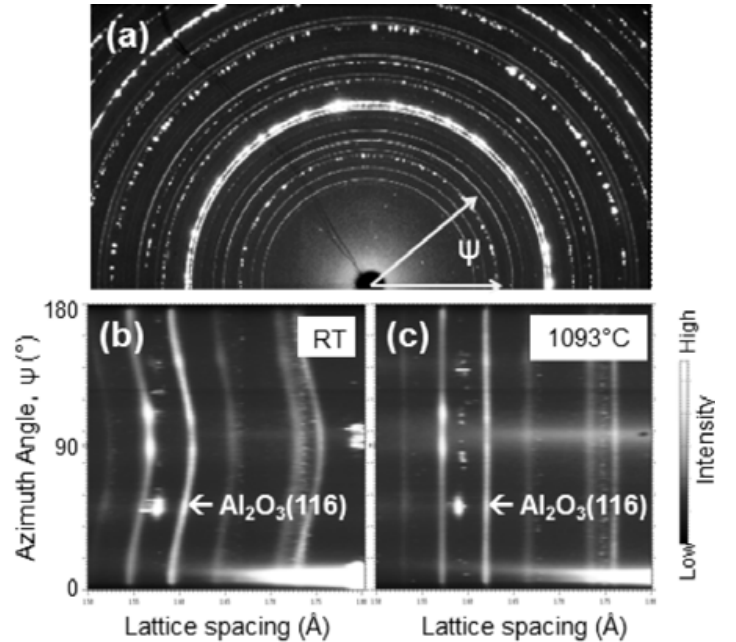

Figure 4. (a) Diffraction rings obtained from the René N5 specimen pre-oxidized at $1093^{\circ} \mathrm{C}$, and the lattice spacing at (b) room temperature and (c) $1093^{\circ} \mathrm{C}$.

Table 2. Room temperature in-plane stresses and strains of the $\alpha-\mathrm{Al}_{2} \mathrm{O}_{3}$.

\begin{tabular}{|l|l|l|l|}
\hline Material & $\begin{array}{l}\text { Pre- } \\
\text { oxidation } \\
\text { temperature } \\
\left({ }^{\circ} \mathbf{C}\right)\end{array}$ & $\begin{array}{l}\text { In-plane } \\
\text { stress, } \sigma_{\mathbf{1 1}} \\
(\mathbf{G P a})\end{array}$ & $\begin{array}{l}\text { In-plane } \\
\text { strain, } \varepsilon_{\mathbf{1 1}} \\
(\boldsymbol{\%})\end{array}$ \\
\hline \multirow{2}{*}{ René N5 } & 1093 & -4.95 & -0.99 \\
\cline { 2 - 4 } & 982 & -3.87 & -0.77 \\
\hline $\begin{array}{l}\text { Vapor phase } \\
\text { aluminde }\end{array}$ & 1093 & -2.71 & -0.54 \\
\cline { 2 - 4 } & 982 & -2.70 & -0.54 \\
\hline
\end{tabular}

\subsection{Oxide growth strains}

\subsubsection{Oxide growth strains at room temperature}

An example of diffraction rings obtained from the oxide layer of the René N5 specimen pre-oxidized at $1093{ }^{\circ} \mathrm{C}$ is shown in Fig. 4a. Figure $4 \mathrm{~b}$ shows the lattice spacing as a function of azimuth angle. Since the specimen was pre-oxidized at elevated temperature, the diffraction rings exhibited significant strains at room temperature due to the contraction of the superalloy. The lattice spacing of the $\alpha-\mathrm{Al}_{2} \mathrm{O}_{3}$ was smaller at 0 and $180^{\circ}$ than at $90^{\circ}$, which indicates that there is an in-plane compressive strain in the $\alpha-\mathrm{Al}_{2} \mathrm{O}_{3}$ layer. Using a MATLAB code $[12,17], d_{\psi=90^{\circ}}$ and $d_{\psi=0^{\circ}}$ of the $\mathrm{Al}_{2} \mathrm{O}_{3}$ (116) reflection were determined, and $\varepsilon_{11}$ and $\sigma_{11}$ were calculated using the Eqs. (1)-(3). The intensities of the $\alpha-\mathrm{Al}_{2} \mathrm{O}_{3}$ diffraction rings are relatively constant from 0 to $180^{\circ}$ (Figs. $4 \mathrm{a}-\mathrm{c}$ ), which indicates that the $\alpha-\mathrm{Al}_{2} \mathrm{O}_{3}$ layer does not have strong grain texture. Table 2 shows the room temperature in-plane stresses and strains in the $\alpha-\mathrm{Al}_{2} \mathrm{O}_{3}$ layer formed on the René $\mathrm{N} 5$ and the vapor phase aluminde coating specimens. All specimens exhibited large in-plane compressive strains up to $1 \%$. The René N5 specimen pre-oxidized at $1093^{\circ} \mathrm{C}$ exhibited a larger compressive in-plane strain than at $982^{\circ} \mathrm{C}$. The vapor phase aluminide specimens had almost same strains regardless of the pre-oxidation temperatures.
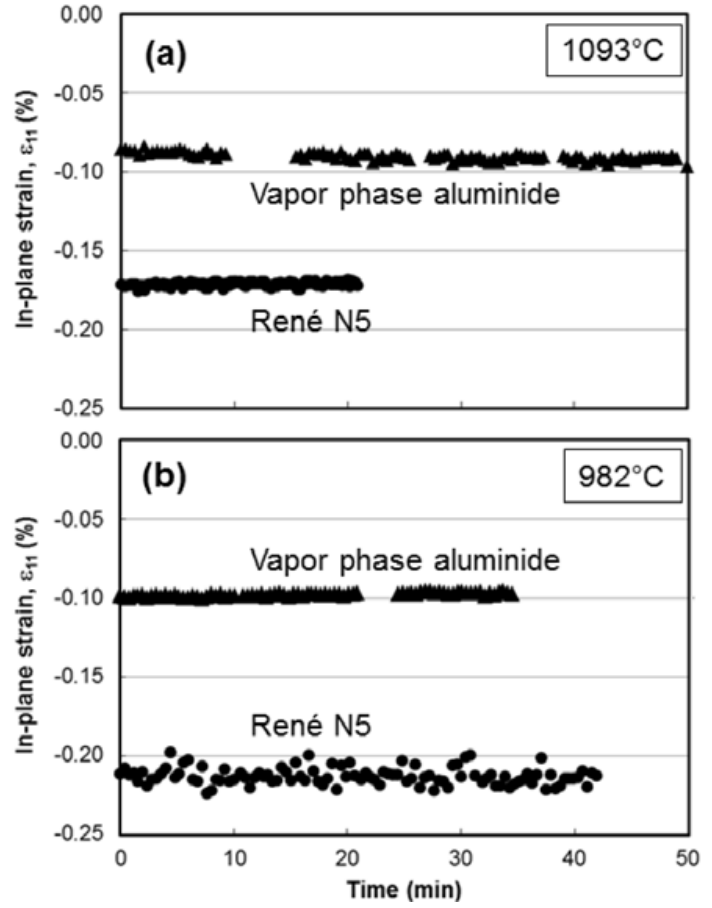

Figure 5. In-plane growth strains of the $\alpha$-A12O3 formed on René $\mathrm{N} 5$ and vapor phase aluminide showing consistent strains during measurement duration at (a) $1093^{\circ} \mathrm{C}$ and (b) $982^{\circ} \mathrm{C}$.

\subsubsection{In-situ oxide growth strain measurements}

Figure $4 \mathrm{c}$ shows the lattice spacing plot of the same specimen obtained after heating to $1093^{\circ} \mathrm{C}$. The lattice spacing of the $\alpha-\mathrm{Al}_{2} \mathrm{O}_{3}$ (116) peak showed little dependency on azimuth angle. However, using the same diffraction peak analysis algorithm, it was confirmed that there was a small in-plane compressive stress and strain. Figure 5 shows the in-plane strains of the $\alpha-\mathrm{Al}_{2} \mathrm{O}_{3}$ layer on the René N5 and the vapor phase aluminide coating specimens during the measurements at $1093^{\circ} \mathrm{C}$ (Fig. 5a) and $982^{\circ} \mathrm{C}$ (Fig. 5b). During the measurements, the oxide growth strains were consistent over the time. These results indicate that strain accumulation due to oxide growth and strain relaxation due to creep are in near equilibrium condition after the pre-oxidation for 68 hours. Table 3 summarises the in-situ measurement results. The $\alpha-\mathrm{Al}_{2} \mathrm{O}_{3}$ had larger in-plane compressive strains on the René N5 specimens compared with the vapor phase aluminide specimens at both temperatures. The oxide growth strain on the René N5 was higher at $982^{\circ} \mathrm{C}$ than at $1093{ }^{\circ} \mathrm{C}$. On the other hand, the oxide growth strain on the vapor phase aluminde specimen did not show temperature dependency.

The dominant source of potential error to the measured strain value is temperature uncertainty. The temperature uncertainty can cause thermal expansion or contraction of the superalloy substrate, which can be as much as $0.02 \%$ strain. The errors from the strain analysis of the $2 \mathrm{D}$ diffraction patterns $[12,17]$ are less than $0.01 \%$, which is much smaller than that from temperature uncertainty. 
Table 3. In-situ in-plane stress and strain of the $\alpha-\mathrm{Al}_{2} \mathrm{O}_{3}$ layer.

\begin{tabular}{|l|l|l|l|}
\hline Material & $\begin{array}{l}\text { Temperature } \\
\left({ }^{\circ} \mathbf{C}\right)\end{array}$ & $\begin{array}{l}\text { In-plane } \\
\text { stress, } \sigma_{\mathbf{1 1}} \\
(\mathbf{G P a})\end{array}$ & $\begin{array}{l}\text { In-plane } \\
\text { strain, } \varepsilon_{\mathbf{1 1}} \\
(\mathbf{\%})\end{array}$ \\
\hline \multirow{2}{*}{ René N5 } & $1093^{\circ} \mathrm{C}$ & -0.75 & -0.17 \\
\cline { 2 - 4 } & $982^{\circ} \mathrm{C}$ & -0.94 & -0.21 \\
\hline $\begin{array}{l}\text { Vapor } \\
\text { phase } \\
\text { aluminde }\end{array}$ & $1093{ }^{\circ} \mathrm{C}$ & -0.40 & -0.09 \\
\cline { 2 - 4 } & $982{ }^{\circ} \mathrm{C}$ & -0.43 & -0.10 \\
\hline
\end{tabular}

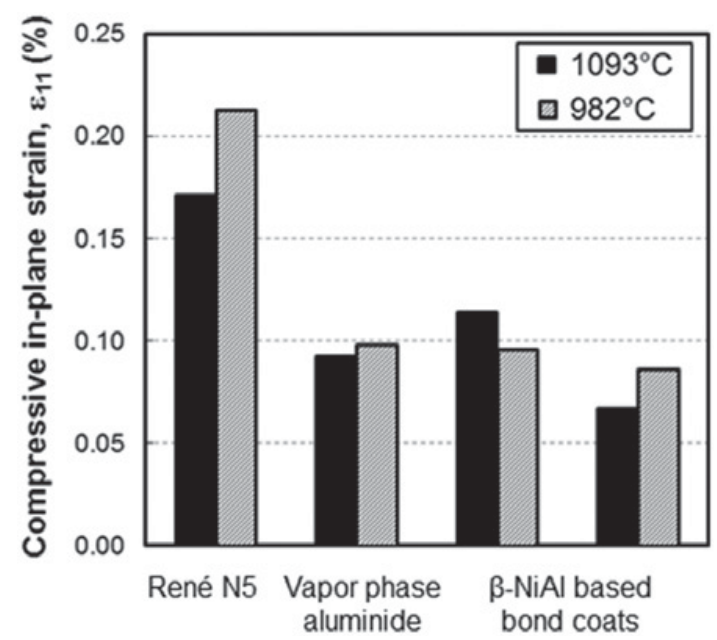

Figure 6. Comparison of the compressive in-plane strains of the $\alpha-\mathrm{Al}_{2} \mathrm{O}_{3}$ layer formed on René N5 single-crystal superalloy and three $\beta$-NiAl based bond coats.

\subsubsection{Oxide growth strains on $\beta-\mathrm{NiAl}$ bond coats}

The same in-situ oxide growth strain measurement approach was applied to two different $\beta$-NiAl based industrial bond coats. Figure6 shows a comparison of the in-plane compressive strains of the $\alpha-\mathrm{Al}_{2} \mathrm{O}_{3}$ layers. The strains measured on three different $\beta$-NiAl based bond coats were consistently smaller than the ones on René N5, and roughly at $-0.1 \%$, independent of both bond coat chemistry and temperature. Smaller inplane compressive oxide growth strains are expected to be beneficial in suppressing both bond coat rumpling and oxide-assisted crack growth. However, the obtained results indicate that it may be difficult to reduce the compressive oxide growth strains on the $\beta$-NiAl based bond coats by modifying bond coat chemistry. Exploration of different bond coat systems outside the $\beta$-NiAl based compositions may be required to identify an alternate path to improve crack growth resistance of the bond coat materials.

\section{Summary}

In-situ measurements of the growth strains of the $\alpha-\mathrm{Al}_{2} \mathrm{O}_{3}$ layers formed on the single-crystal superalloy and the $\beta$ $\mathrm{NiAl}$ based bond coats were performed using high energy synchrotron X-rays. The followings were observed:

(1) At elevated temperatures, the in-plane growth strains of the $\alpha-\mathrm{Al}_{2} \mathrm{O}_{3}$ were compressive in both René N5 superalloy and vapor phase aluminide bond coat specimens.

(2) The in-plane compressive growth strains of the $\alpha-\mathrm{Al}_{2} \mathrm{O}_{3}$ formed on the $\beta$-NiAl based bond coats were smaller than those on the superalloy specimen, and independent of bond coat chemistry and temperature.

The authors are thankful to S.J. Duclos, M.L. Blohm, PR Subramanian for their program support. J.R. Cournoyer, E.H. Hearn of GE Global Research, and Ali Mashayekhi and Roger Ranay at Sector 1 of APS are greatly acknowledged for their technical support.

Use of the Advanced Photon Source, an Office of Science User Facility operated for the U.S. Department of Energy (DOE) Office of Science by Argonne National Laboratory, was supported by the U.S. DOE under Contract No. DE-AC02$06 \mathrm{CH} 11357$.

\section{References}

[1] A. Suzuki, M.F.X. Gigliotti, B.T. Hazel, D.G. Konitzer, T.M. Pollock, Metall. Mater. Trans. A, 41A, 947 (2010)

[2] A.G. Evans, D.R. Mumm, J.W. Hutchinson, G.H. Meier, F.S. Pettit, Prog. Mater. Sci., 46, 505 (2001)

[3] A.G. Evans, M.Y. He, A. Suzuki, M. Gigliotti, B. Hazel, T.M. Pollock, Acta Mater., 57, 2969 (2009)

[4] M.Y. He, A.G. Evans, Acta Mater., 58, 583 (2010)

[5] T.M. Pollock, B. Laux, C.L. Brundidge, A. Suzuki, M.Y. He, J. Am. Ceram, Soc., 94, S136 (2011)

[6] B.W. Veal, A.P. Paulikas, P.Y. Hou, Nature Materials, 5, 349 (2006)

[7] B.W. Veal, A.P. Paulikas, R.C. Birtcher, Appl. Phys. Lett., 89, 161916 (2006)

[8] P.Y. Hou, A.P. Paulikas, B.W. Veal, Mat. Sci. Forum, 522-523, 433 (2006)

[9] B.W. Veal, A.P. Paulikas, P.Y. Hou, Appl. Phys. Lett., 90, 121914 (2007)

[10] B.W. Veal, A.P. Paulikas, B. Gleeson, P.Y. Hou, Surf. Coat. Tech., 202, 608 (2007)

[11] B.W. Veal, A.P. Paulikas, J. Appl. Phys., 104, 093525 (2008)

[12] J.D. Almer, G.A. Swift, J.A. Nychka, E. Üstündag, D.R. Clarke, Mat. Sci. Forum, 490-491, 287 (2005)

[13] B. Laux, T.M. Pollock (to be published)

[14] T.M. Pollock, D.M. Lipkin, K.J. Hemker: MRS Bulletin, 37, 923 (2012)

[15] I.C. Noyen, J.B. Cohen, Residual Stress Measurement by Diffraction and Interpretation (Springer, New York, 1987)

[16] B.B. He, Two-dimensional X-ray Diffraction (Wiley, New Jersey, 2009)

[17] S. Sakaguchi, N. Murayama, Y. Kodama, F. Wakai, J. Mat. Sci. Lett., 10, 282 (1991)

[18] M. Fukuhara, I. Yamauchi, J. Mat. Sci., 28, 4681 (1993) 